African Journal of Drug \& Alcohol Studies, 9(2), 2010

Copyright (C) 2010, CRISA Publications

\title{
SEXUAL RISK BEHAVIOURS AMONG PATIENTS ADMITTED FOR SUBSTANCE USE DISORDER AND SCHIZOPHRENIA IN A PSYCHIATRIC HOSPITAL IN LAGOS, NIGERIA
}

\author{
Veronica O. Nyamali ${ }^{1}$, Olufemi Morakinyo ${ }^{2} \&$ Rahmaan Lawal $^{1}$ \\ ${ }^{1}$ Federal Neuropsychiatric Hospital, Yaba, Lagos. Nigeria, \\ ${ }^{2}$ Department of Mental Health, College of Medical Sciences, \\ University of Benin, Benin City, Nigeria
}

\begin{abstract}
Researchers have reported that abuse of psychoactive substances play a major role in HIV transmission among drug users while those with a diagnosis of schizophrenia may also be at high risk for HIV infection. This is a cross-sectional and comparative study of consecutive and consenting patients admitted at the Federal Neuropsychiatric Hospital Yaba between April and December 2008, aimed at comparing HIV risk behaviours of patients with substance use disorder and those with schizophrenia, comparing the findings between the two groups and determining the socio-demographic factors in each group associated with such behaviours. The results showed that subjects using psychoactive substances were more involved in sexual activity than those with schizophrenia. Both groups of subjects engaged in HIV risk behaviours such as having multiple casual partners (Substance users 21.5\%, schizophrenia 9.5\%). Non-use of condom with casual partners (Substance users $25.4 \%$, Schizophrenia 36.7\%) and history of sexually transmitted diseases like genital discharge (Substance users 4.0\%, Schizophrenia 15.0\%) were more in those with Schizophrenia. In conclusion, both groups of patients engaged in high risk sexual behaviours that could predispose them to HIV infection. It was recommended that concerted efforts should be made to establish HIV prevention programmes for both groups of psychiatric patients.
\end{abstract}

KeY WorDs: sexual, risk behaviour, schizophrenia, substance use disorder, inpatients, lagos nigeria

\section{INTRODUCTION}

Human Immunodeficiency Virus (HIV), the virus that causes Acquired Immunodeficiency Syndrome (AIDS) has become one of the most serious health and development challenges (Kaiser 2009). In spite of the enormous work carried out on its etiology, mode of transmission and treatment, HIV infection has continued its global spread. There were 33.4 million people living with HIV/AIDS (PLWHA) in 2008, up from 29 million in 2001 (UNAIDS /WHO, 2008).

Behavioural risk factors for HIV identified in people with mental illness include low rates of condom use during sexual activity

Corresponding author: Nyamali Veronica O. M.B. CH. B. (OAU Ile-Ife), FWACP, Consultant Psychiatrist, Federal Neuropsychiatric Hospital, Yaba, Lagos. Phone: +234 807307 5454; E-mail: yemisyamali@yahoo.com 
(Sacks et al ,1990; Jeffrey et al ,1999); having multiple/same sex partners and sex in exchange for drugs, shelter or basic survival needs (Kalichman et al 1994, Kelly et al, 1995), coercion into unwanted sexual activity (Weinhardt et al, 1999, Coverdale and Turbott, 2000); living in impoverished inner city areas with high rates of drug use and sexually transmitted disease (Jeffrey et al, 1991): coexisting substance use patterns (Blanchard et al, 2000, Carey et al, 2003) especially the use of alcohol, cannabis and crack cocaine (Chopra et al, 1996, Carey et al, 1997). Intravenous drug use and needle sharing has also been reported (Grassi et al, 1999, Carey et al, 2001).

Use of psychoactive substances also plays a major role in HIV transmission among noninjecting drug users (Jeffrey, 2002). Excessive use of alcohol (intoxication, binge drinking) has been associated with the development of neuro-psychiatric conditions, physical injuries, unsafe sexual behaviour and the use of other psychoactive drugs (Odejide, 2006). Similarly, like people with schizophrenia, injecting drug users are particularly vulnerable to HIV as a result of sharing of contaminated injecting equipment and high-risk sexual behaviours. It has been documented that psychiatric patients particularly those with a diagnosis of schizophrenia may be at high risk of HIV infection (Gray and Brewin, 2002). The risk behaviours include sharing injection needles during intravenous drug use, promiscuity associated with unprotected sex and high-risk sexual activity after using drugs.

Although, a considerable body of research on HIV/AIDS - especially on knowledge, attitude, and risk behaviour in various groups has been reported in Nigeria (Okpani and Okpani 2000, Okeke et al 2003), reports of studies on HIV risk behaviour are rather scanty among the mentally ill patients.

\section{METHOD}

Setting/Duration: The study was conducted at the Federal Neuropsychiatric Hospital
Yaba over a period of 8 months (April to December, 2008).

Participants: The study group was made up of two hundred consecutive and consenting patients with substance use disorder and the comparative group consisted of 200 patients who satisfied ICD-10 (as diagnosed by a consultant psychiatrist) criteria for schizophrenia.

Inclusion Criteria: The subjects were aged between 18 to 64years, had been on admission at the Federal Neuropsychiatric Hospital for at least 2 weeks, and use of substance/first episode of schizophrenia must at least be 12 months prior to the study.

Exclusion Criteria: Subjects who refused to give consent, those whose use of substance/ first episode of schizophrenia was less than 12 months prior to the study and those with comorbid substance use and schizophrenia were excluded.

Instruments: A questionnaire was specially constructed with items extracted from the following:

- World Health Organization Drug Injecting Study Questionnaire (Phase II version 2): It has been standardized to investigate HIV infection and risk behaviours among those who use drugs (injecting and non injecting), for investigation of overdose, and adverse consequences of drug use. Core sections extracted from it includes demographics, injection drug use and sexual behaviours. The instrument has been validated for use in Nigerian population (Adelekan et al, 2000).

- World Health Organization Questionnaire for Student Drug Use Survey. This was used to obtain information on non-injecting drug use, frequency and age of first use of 14 types of psychoactive substances. A 22item semi-structured questionnaire used previously in this environment and found to be reliable and valid (Smart et al, 1980).

- National HIV/AIDS and Reproductive Health Survey questionnaire (NARHS, 2003): This was used to obtain information on sexually transmitted diseases. It has also been previously used and validated in this environment (Federal Ministry of Health Nigeria, 2003). 
The questionnaire was administered by interviewer's method. Clearly defined in the questionnaire were the following: a primary partner is someone who is the most important regular sex partner, a casual partner is someone who has had sexual relations with the subject other than the primary partner while a client is someone who gave money, goods or drugs for sex. The specific HIV risk behaviours which were considered in the 12 months prior to the study were: non-use of condom, having multiple sexual partners and history of having sexually transmitted diseases. All the participants responded to the instruments.

Sampling Procedure: Purposive sampling method was used to recruit participants. The process involved getting into the wards, requesting from nurses their nominal rolls (list of patients on admission) to know those who had schizophrenia and those who had pure substance use disorders who have been on admission for at least 2 weeks. The substance used by each patient was based on the patients' self-report, verbal reports from relatives/ friends who could be reached for information about the patients and verbal reports from the doctors and nurses managing the patients in the ward. Information was also gotten from referral letters brought by the patients at presentation at the emergency unit. In addition, a clinical assessment was carried out on each of those who used substance to determine the substance and mode of its use (looking out specifically for stained teeth, dark coloured lips, needle tracks, injection abscesses /wound sites, any signs suggestive of nasal perforation and so on). The results of urine drug screen done routinely in the hospital were noted to confirm their diagnoses.

\section{RESULTS}

Socio-demographic characteristics of respondents: A total of 400 adults comprising 200 patients admitted for the use of psychoactive substances and 200 inpatients receiving treatment for schizophrenia participated in the study. The age of the subjects ranged from 18 to 64 years (sexually active and reproductive age group) but the age comparison was done only for those between 18 and 49years (the drug group [the study group] was younger compared with the schizophrenia group [the comparison group] hence an attempt was made to control for age for better comparison).

As shown in Table 1, the mean age of substance users was 30.16 years $(\mathrm{SD} \pm 7.12)$ while that of patients with schizophrenia was 34.50 years ( \pm SD 7.98). The difference in the two means was statistically significant (t- test $p<0.05$ ). The majority of the substance users were males $(88.5 \%)$ while there was an almost equal distribution in the gender of those with schizophrenia $\left(\chi^{2}\right.$ $=0.0001 p<0.05)$. Although, majority of the participants in the two groups were married, a higher proportion of the substance users were married (76\%) compared subjects who had schizophrenia $(63.5 \%)\left(\chi^{2} \mathrm{p}<0.05\right)$.

The subjects were fairly well educated. Proportionally, more of the substance users (52.5\%) compared with subjects who had schizophrenia $(48.5 \%)$ completed secondary school education $\left(\chi^{2}\right.$ test $\left.=0.424 \mathrm{p}<0.05\right)$. A lower proportion of the substance users (42.5\%) compared with subjects who had schizophrenia $(50.5 \%)$ were employed $\left(\chi^{2}=\right.$ $0.058 \mathrm{p}>0.05)$. Most of the subjects in the 2 groups were into elementary occupations, although the substance users in this category $(30.4 \%)$ were proportionally fewer than those with schizophrenia (37.4\%).

\section{HIV risk behaviours}

Sexual Practice by Subjects: A smaller proportion of those who use substance (18.5\%) compared with those who have schizophrenia $(46 \%)$ were not sexually active (i.e. did not have sex) in the 12 months preceding the study $\left(\chi^{2}\right.$ test $\left.=0.000 \mathrm{p}<0.05\right)$. Similarly, the frequency of sexual activity was generally greater in the substance users $(36.5 \%)$ than subjects with schizophrenia (17\%) as shown in Figure 1 below $\left(\chi^{2}\right.$ test $\left.=0.000=0.000 p<0.05\right)$. The frequency of sexual activity with casual partners was more in the substance users $(10.5 \%)$ compared with subjects who had schizophrenia $\left[5.5 \%, \chi^{2}\right.$ test $\left.=0.000, \mathrm{p}<0.05\right]$. 
Table 1. Socio-demographic Characteristics of the Substance Users and those with Schizophrenia

\begin{tabular}{|c|c|c|c|}
\hline Variables & $\begin{array}{c}\text { Substance Users } \\
\text { n (\%) }\end{array}$ & $\begin{array}{c}\text { Schizophrenia } \\
\text { n (\%) }\end{array}$ & $\begin{array}{c}\text { Statistical } \\
\text { Significance }\end{array}$ \\
\hline \multicolumn{4}{|l|}{ Age (Years) } \\
\hline $18-25$ & $53(27.7)$ & $27(14.7)$ & $* * \mathrm{p}=0.000$ \\
\hline $26-33$ & $87(45.6)$ & $63(34.2)$ & \\
\hline $34-41$ & $32(16.8)$ & $51(27.7)$ & \\
\hline $42-49$ & 19(9.9) & $43(23.4)$ & \\
\hline \multicolumn{4}{|l|}{ Gender } \\
\hline Male & $169(88.9)$ & $90(48.9)$ & $* * \mathrm{p}=0.000$ \\
\hline Female & $22(11.5)$ & $94(51.1)$ & \\
\hline \multicolumn{4}{|l|}{ Marital Status } \\
\hline Single & $29(14.5)$ & $40(20.0)$ & $* \mathrm{p}=0.051$ \\
\hline Married & $152(76.0)$ & $127(63.5)$ & \\
\hline Separated/Divorced & $18(9.0)$ & $31(15.5)$ & \\
\hline Widow & $1(0.5)$ & $2(1.0)$ & \\
\hline \multicolumn{4}{|l|}{ Educational Attainment } \\
\hline Secondary or Less & $95(47.5)$ & $103(51.5)$ & $* p=0.424$ \\
\hline Post Secondary & $105(52.5)$ & $97(48.5)$ & \\
\hline \multicolumn{4}{|l|}{ Employment Status } \\
\hline Employed & $92(46.0)$ & $88(44.0)$ & $* \mathrm{p}=0.058$ \\
\hline Unemployed & $85(42.5)$ & $101(50.5)$ & \\
\hline Student/Apprentice & $23(11.5)$ & $11(5.5)$ & \\
\hline
\end{tabular}

$* * \mathrm{p}<0.05=$ Significant, $* \mathrm{p}>0.05=$ Not significant

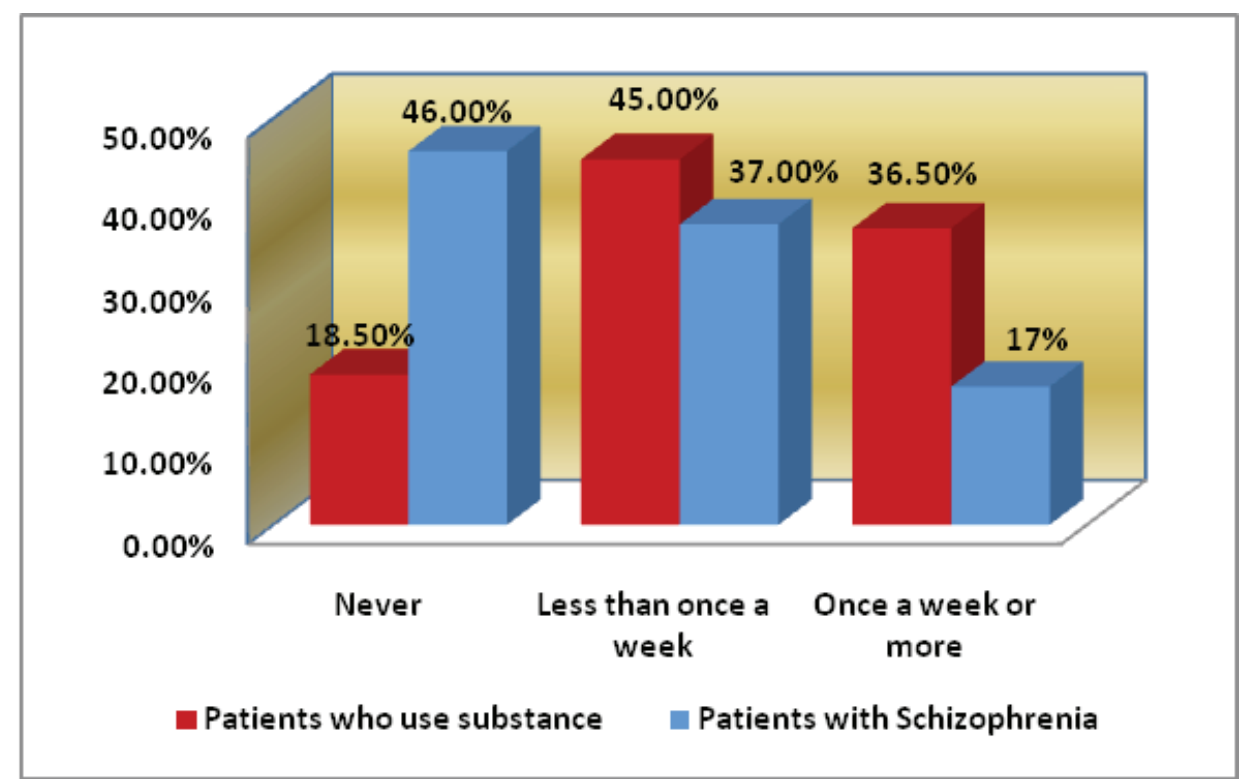

Figure 1. Frequency of sexual activity of patients with substance use disorder and patients with schizophrenia in the last 12 months before the study. 
Multiple sexual partners : A greater proportion of the substance users $(21 \%)$ had multiple primary sex partners compared with patients who had schizophrenia $(8 \%)\left(\chi^{2}\right.$ test $=$ $0.001 \mathrm{p}<0.05$ ) Table 2. So also, $21 \%$ percent of the substance users compared with only $9.5 \%$ of patients with schizophrenia had multiple casual sex partners $\left(\chi^{2}\right.$ test $\left.=0.003 p<0.05\right)$ Table 2 . The substance users had a higher number of clients [2 or more] compared with patients who had schizophrenia, $27.5 \%$ of the substance users had multiple clients [ 2 or more] compared with only $6.5 \%$ of those who had schizophrenia $\left(\chi^{2}\right.$ test $\left.=0.000 p<0.05\right)$ Table 2 . Two percent of the substance users each had 2 or more same sex partners while only one patient with schizophrenia had 4 same sex partners.

Condom Use: One hundred and sixty one subjects $(40.3 \%)$ of the subjects in the study had no primary partners while the remaining $239(59.7 \%)$ had. A smaller proportion of the substance users $(44.3 \%)$ compared with subjects who had schizophrenia $(68 \%)$ never used condoms with their primary partners in the last 12 months $\left(\chi^{2}\right.$ test $\left.=0.000 \mathrm{p}<0.05\right)$ Table 3. Majority of the subjects, 311(77.8\%) had no casual partners, while only 89 (22.2\%) had. About one-quarter of the substance users (25.4\%) compared with $36.7 \%$ of subjects who had schizophrenia never used condoms with their casual partners $\left(\chi^{2}\right.$ test $\left.=0.012 p<0.05\right)$ Table 3. Most of the subjects $308(77 \%)$ had no clients, thus only the remaining 92 (23\%) were assessed for condom use. A lower percentage of the substance users (13.9\%) compared with subjects who had schizophrenia $(20 \%)$ never used condoms with their clients $\left(\chi^{2}\right.$ test $=0.759$ $\mathrm{p}>0.05$ ) (Table 3). Only 5 (1.3\%) of the subjects who had same sex partners were assessed for condom use. All the substance users who had same sex partners $4(100 \%)$ never used condoms with them while the only patient with schizophrenia who belonged to this group used condom occasionally (only 5 participants in the study had same sex partners).

History of sexually transmitted diseases: A lower proportion of the substance users (4\%) compared with patients who had schizophrenia $(15 \%)$ had genital discharge, similarly a lower proportion of the substance users $(5.5 \%)$ compared with patients who had schizophrenia $(16.5 \%)$ had genital itching $(\mathrm{p}<0.05)$ Table 4 .

Table 2. Number of sexual partners of the substance users and patients with schizophrenia 12 months preceding the study

\begin{tabular}{|c|c|c|c|}
\hline Types of Sexual Partner(s) & $\begin{array}{c}\text { Substance Users } \\
\mathrm{n}(\%)\end{array}$ & $\begin{array}{c}\text { Schizophrenia } \\
\text { n }(\%)\end{array}$ & $\begin{array}{c}\text { Statistical } \\
\text { Significance }\end{array}$ \\
\hline \multicolumn{4}{|l|}{ Primary Partner(s) } \\
\hline No partner & $69(34.5)$ & $92(46.0)$ & $* * \mathrm{p}=0.001$ \\
\hline One partner & $89(44.5)$ & $92(46.0)$ & \\
\hline Two or three partners & $36(18.0)$ & $12(6.0)$ & \\
\hline Four or more partners & $6(3.0)$ & $4(2.0)$ & \\
\hline \multicolumn{4}{|l|}{ Casual Partner(s) } \\
\hline No partner & $141(70.5)$ & $170(85.0)$ & $* * \mathrm{p}=0.003$ \\
\hline One partner & $16(8.0)$ & $11(5.5)$ & \\
\hline Two or three partners & $28(14.0)$ & $15(7.5)$ & \\
\hline Four or more partners & $15(7.5)$ & $4(2.0)$ & \\
\hline \multicolumn{4}{|l|}{ Clients } \\
\hline No partner & $128(64.0)$ & $180(90.0)$ & $* * \mathrm{p}=0.000$ \\
\hline One partner & $17(8.5)$ & $7(3.5)$ & \\
\hline Two or three partners & $37(18.5)$ & $9(4.5)$ & \\
\hline Four or more partners & $18(9.0)$ & $4(2.0)$ & \\
\hline
\end{tabular}

\footnotetext{
$* * p<0.05=$ Significant, $* p>0.05=$ Not significant
} 
Table 3. Condom use with sexual partners of substance users and patients with schizophrenia 12 months preceding the study

\begin{tabular}{|c|c|c|c|}
\hline Types of Sexual Partner(s) & $\begin{array}{c}\text { Substance Users } \\
\text { n }(\%)\end{array}$ & $\begin{array}{c}\text { Schizophrenia } \\
\text { n (\%) }\end{array}$ & $\begin{array}{c}\text { Statistical } \\
\text { Significance }\end{array}$ \\
\hline \multicolumn{4}{|l|}{ Primary Partner(s) } \\
\hline Never & $58(44.3)$ & $74(68.5)$ & $* * \mathrm{p}=0.000$ \\
\hline Occasionally/half the time & $41(31.3)$ & $26(24.1)$ & \\
\hline Always & $32(24.4)$ & $8(7.4)$ & \\
\hline \multicolumn{4}{|l|}{ Casual Partner(s) } \\
\hline Never & $15(25.4)$ & $11(36.7)$ & $* * \mathrm{p}=0.012$ \\
\hline Occasionally/half the time & $20(33.9)$ & $16(53.3)$ & \\
\hline Always & $24(40.7)$ & $3(10.0)$ & \\
\hline \multicolumn{4}{|l|}{ Clients(s) } \\
\hline Never & $10(13.9)$ & $4(20.0)$ & $* \mathrm{p}=0.759$ \\
\hline Occasionally/half the time & $26(36.1)$ & $6(30.0)$ & \\
\hline Always & $36(50.0)$ & $10(50.0)$ & \\
\hline
\end{tabular}

${ }^{* *} p<0.05=$ Significant, ${ }^{*} p>0.05=$ Not significant

Similarly, only $4 \%$ of the substance users compared with $10.5 \%$ of patients with schizophrenia had genital ulcer/sore $\left(\chi^{2}\right.$ test $=0.012$ $\mathrm{p}<0.05$ ) Table 4.

\section{Relationship between socio-demographic characteristics and HIV risk behaviour:}

There was a significant difference in gender, level of education and marital status between the two groups with regard to condom use. Proportionally, more of the subjects who did not use condoms with their casual partners or clients were males who were substance users $(73.7 \%)$ compared with males who had schizophrenia (26.3\%). Similarly, those who did not use condoms with these partners who had low level of education were mainly substance users (68.4\%) compared with subjects who had schizophrenia (53.3\%) while proportionally more of those who did not use condom were those with schizophrenia who were not married $(100 \%)$ compared with the substance users $(73.7 \%)$. Concerning gender, there is a significant difference between those who

Table 4. History of sexually transmitted diseases in substance users and patients with schizophrenia 12 months preceding the study.

\begin{tabular}{|c|c|c|c|}
\hline Types of Sexual Partner(s) & $\begin{array}{c}\text { Substance Users } \\
\text { n (\%) }\end{array}$ & $\begin{array}{c}\text { Schizophrenia } \\
\text { n (\%) }\end{array}$ & $\begin{array}{c}\text { Statistical } \\
\text { Significance }\end{array}$ \\
\hline \multicolumn{4}{|l|}{ Genital Discharge } \\
\hline Yes & $8(4.0)$ & $30(15.0)$ & $* * \mathrm{p}=0.000$ \\
\hline No & 192(96.0) & $170(85.0)$ & \\
\hline \multicolumn{4}{|l|}{ Genital Itching } \\
\hline Yes & $11(5.5)$ & $33(16.5)$ & $* * \mathrm{p}=0.000$ \\
\hline No & 189(94.5) & $167(83.5)$ & \\
\hline \multicolumn{4}{|l|}{ Genital Ulcer/Sore } \\
\hline Yes & $8(4.0)$ & $21(10.5)$ & $* * \mathrm{p}=0.012$ \\
\hline No & 192(96.0) & $179(89.5)$ & \\
\hline
\end{tabular}

${ }^{* *} p<0.05=$ Significant, ${ }^{*} p>0.05=$ Not significant 
reported having sexually transmitted diseases in the two groups. Being male was significantly associated with history of having STD in subjects with substance use disorder $(66.7 \%)$ than in subjects with schizophrenia $(26.3 \%)$. There is a significant difference in age between those who had sex with multiple casual partners in the two groups. Those 30years and younger who had sex with multiple casual partners were mainly substance users (substance users $62.7 \%$, subjects with schizophrenia $38.5 \%$ ).

\section{DISCUSSION}

Most of the patients fell within the age range 15-49 years which is the sexually active age range where most subjects engaged frequently in sexual activity. The subjects used in sentinel studies in Nigeria (for example NARHS 2003) were in this age range. The mean age of substance users was lower than that of those who had schizophrenia most probably because substance use is more prevalent in adolescents. Majority of the patients were married probably because they were selected hospital patients who have been coming for treatment and whose relations are able to pay for treatment. More of the substance users compared with those who had schizophrenia were married ( $76 \%$ and $63.5 \%$ respectively). This finding is similar to previous reports from other countries thatindividuals with schizophrenia have difficulty in establishing stable, social and sexual relationships which may perhaps affect marriage (Howarth and Cournos ,1999). In a study done in the USA, a high proportion (93\%) of cohort of mentally ill patients were reported to be unmarried (Kelly et al, 1992) while Ogunsemi et al. (2007) in a study done in Nigeria reported that $68 \%$ of their respondents were unmarried. This is comparable to the finding $(63.5 \%)$ in the present study.

Both groups of patients were fairly well educated however their low employment status (substance users 46\%, schizophrenia 44\%) may be a reflection of their illness and the economic situation in the country. Proportionally, more of the substance users compared with those who had schizophrenia completed secondary school education, however a lower proportion of the substance users compared with those who had schizophrenia completed tertiary education. Lower educational attainment was one of the significant correlates of HIV positivity identified among substance users in Lagos (Lawal and Ogunsemi, 2005). Up to a third of respondents in each group were in elementary occupations such as shoe cleaning, farming, domestic and related helps etc. This may be explained by the societal stigma and hence limited educational attainment associated with both conditions. Schizophrenia is known to be a progressively deteriorating disorder associated with deficits in various cognitive functions especially attention, memory and executive functions all of which could affect intellectual functioning or academic performance.

Low employment status may predispose substance users to engaging in menial jobs while others can resort to indecent and illegal ways of making money like sex trading/prostitution and stealing/ theft. About two-thirds of the substance users (non-injecting) in this study were cannabis users. Chronic use of cannabis is known to be associated with a condition known as "amotivational syndrome" which could be an important factor that may affect either educational or academic performance.

\section{Level of sexual activity of the participants}

A greater proportion of the substance users (81\%) compared with those who had schizophrenia (54\%) were involved in sexual activity in the 12 months preceding the study. This is not surprising because most of the psychoactive substances can enhance sexual activity. The low sexual activity seen in subjects with schizophrenia may be due to the nature of the disturbances they experience that do not include high libidinal cravings and characterize high risk sexual behaviour (Mckinnon et al, 1996). It may also be as a result of the side effects of anti cholinergic effects of antipsychotic medication, for example poor erection that may result from anti cholinergic treatment. 


\section{Multiple partners}

Proportionally, more of the substance users compared with those who had schizophrenia had multiple partners. This is an indication that concerning this risk factor, the substance users took higher risk. Eight percent and 9.5\% of the subjects with schizophrenia had multiple primary and casual partners respectively. This contrasts the results proportions of a study done in Italy among patients with schizophrenia (Grassi et al, 1999) where a high percentage had multiple partners (58\%), 45\% had clients and $37 \%$ had casual partners. This could be due to methodological differences such as recruitment method of both in and out patients and the small sample size of patients. Having multiple partners is a risky sexual behaviour which encourages the spread of HIV and other sexually transmitted diseases. However, the proportion of those with multiple sexual partners reported by the participants was less than those reported in some studies done among the general population. For example, Olayinka and Osho (1997) reported that in their cohort of sexually active subjects from the western part of Nigeria, $60 \%$ of naval officers had multiple sexual partners, Olley and Rotimi (2003) also reported that $55 \%$ of undergraduates had multiple partners. In his own report among female apprentice tailors, Ajuwon et al (2002) found that $52 \%$ had multiple partners. The present findings could be compared with the result of other studies where $31 \%$ and $24 \%$ of adolescents in Enugu (Okeke 2003) and Port Harcourt (Okpani and Okpani 2000) respectively had multiple partners.

\section{Non-use of condom}

Non-use of condom with primary partners was more prevalent in those who had schizophrenia (68.5\%) compared with those who had substance use disorder (36.7\%). This may be because those with schizophrenia are more likely to be careless as a result of their illness and their lack of insight. Non-use of condom in substance users is a common finding because of their perceived vulnerability to HIV through their sexual behaviour pattern, a dislike of condom use and difficulty negotiating condom use with partners. Studies of condom use by persons with mental illness in other countries were not consistent. McKinnon et al. (1996) in New York reported non-use of condom in $58.1 \%$ of their cohorts of persons with mental illness patients while Cournos et al. (1994) reported that condom usage among those with schizophrenia was uncommon. In Italy, about $41 \%$ of patients with schizophrenia reported non-use of condom (Grassi et al., 1999). In this study, a higher proportion of subjects with schizophrenia $(68.5 \%, 36.7 \%$ and $20 \%)$ did not use condom at all with their primary partners, casual partners and clients respectively.

\section{Sexually Transmitted Diseases}

Subjects with schizophrenia lead a less sexually active life compared with those who use substance. Even then, they are less inclined to use condom whenever they have sexual intercourse either with their primary partners or any other partner. It is therefore not surprising that they have a richer history of sexually transmitted diseases than the substance users. Many of the episodes of sexual intercourse may probably have occurred against their will (Weinhardt et al., 1999, Coverdale and Turbott, 2000). Sex in exchange for shelter or basic survival needs have also been reported in the persons with mental illness (Carey et al., 2001). This highrisk behaviour by subjects with schizophrenia may be due to impairment of judgment and lack of insight into their illness.

In conclusion, the results of this study demonstrated the vulnerability of patients who have substance use disorders and those with schizophrenia who both engaged in high risk sexual behaviours that could predispose them to contracting HIV infection. Those who use substance were more involved in sexual activity than those with schizophrenia.

It is recommended that deliberate efforts should be made to establish HIV prevention programmes for both groups of patients. Furthermore, based on their consents, a careful and regular clinical assessment of HIV risk behaviours is also necessary. Future research in 
designing a behavioural modification scheme for these groups is needed.

\section{REFERENCES}

Adelekan, M.L., Lawal, R. A., Akinhanmi, A. O. (2000). Injecting drug use and associated health consequences in Lagos, Nigeria: Findings from WHO phase II Injecting drug use study. In: Proceedings from the 2000 Global Research Network Meeting Report. July 5-7 Durban, South Africa.

Blanchard, J.J., Brown, S.A., Horan, W.P., \& Sherwood, A.R. (2000). Substance use disorders in schizophrenia: review, integration, and a proposed model. Clinical Psychology Review, 20, 207, 234-256.

Carey, M.P., Carey, K.B., \& Kalichman, S.C. (1997). Risk for human immunodeficiency virus (HIV) infection among adults with a severe mental disorder. Clinical Psychology Review, 17, 271-291.

Carey, M.P., Carey, K.B., Maisto S., A., Gordon, C., M., \& Vanable, P.A., (2001). Prevalence and correlates of Sexual Activity and HIV - Related Risk behaviour among psychiatric out patients. Journal of Consulting and Clinical Physiology, 69, 846-850.

Carey, M.P., Chandra, P.S., Carey, K.B., Neal, D. (2003). Predictors of HIV risk behaviour among men seeking treatment for substance in India. Archives of Sexual Behaviour, 32, 339-349.

Cournos, F., Guido, J.R., Coomaraswamy, S., Meyer-Bahlburg, H., Sugden, R., Howarth, E. (1994). Sexual activity and risk of HIV infection among patients with schizophrenia. American Journal of Psychiatry, 151, 228-232.

Coverdale, J.H., Turbott, S.H., (2000). Sexual and Physical abuse of chronically ill psychiatric outpatients compared with a matched sample of medical outpatients. Journal of Nervous and Mental Disease, 188, 440-445.

Grassi, L.,Pavanati, M., Cardelli, R. (1999). HIV-risk behaviour and knowledge about
HIV/AIDS among patients with schizophrenia. Psychological Medicine, 29(1), 171-179.

Gray, R \& Brewin, E (2002). A review of the literature on HIV infection and schizophrenia : implications for research, policy, and clinical practice. Journal of Psychiatry Ment Health Nurs, 9, 405-409.

Howarth, E. \& Cournos, F. (1999).Schizophrenia and other psychotic disorder. In Psychiatry. Cutler, J. L., \& Marcus, E. R. (eds.), Saunders Text and Review Series (pp. 64-80). Philadelphia: Saunders.

Integrated Biological \& Behavioural Surveillance Survey (IBBSS) of HIV/STI Report (2007). A Publication of the Federal Ministry of Health, Abuja, Nigeria.

Jeffrey, A.K., Debra, A.M., Bahr, G.R et al. (1991). AIDS/HIV Risk behaviours among the chronic mentally ill. American Journal of Psychiatry, 149, 886- 889.

Jeffrey, N. H. (2002). Substance Abuse and HIV. The Hopkins HIV Report. Baltimore, MD: Springer.

Kelly, J.A., Murphy, D.A., Bahr, G.R. (1992). AIDS/HIV risk behaviours in the chronic mentally ill. American Journal of Psychiatry, 149, 886- 889.

Kelly, J.A., Murphy, D.A., \& Sikkema, K.. J. (1995). Predictors of high and low levels of HIV risk behaviours among adults with chronic mental illness. American Journal of Psychiatry, 46, 813- 818.

Mckinnon, K., Cournos, F., Sugden, R., et al. (1996). The relative contributions of Psychiatric symptoms and AIDS knowledge to HIV risk behaviours among people with severe mental illness. Journal of Clinical Psychiatry, 57, 506- 513.

National HIV/AIDS \& Reproductive Health Survey NARHS (2003) A Publication of the Federal Ministry of Health, Abuja. Nigeria.

Odejide, A. O. (2006). Public health problems caused by harmful use of alcohol: Commentary. African Journal of Drug and Alcohol Studies, 5(1), 75-77.

Ogunsemi, O. O., Lawal, R. A,. Okulate, T. O., Alebiosu, C. O., Olatawura, M. 
O. (2006). A comparative study of the knowledge, attitudes and risk behaviours of schizophrenic and diabetic patients in regard to HIV in Nigeria. Journal of the International AIDS Society, 8 (4), 42.

Ogunsemi, O. O., Lawal, R. A., Okulate, G. T. (2007). The knowledge and risk behaviours of Nigerian schizophrenics about HIV/AIDS. Nigerian Medical Practitioner, 52, (4) 85-90.

Okeke, T. A. (2003). Sexual behaviour and contraceptive practice among Nigerian adolescents in Enugu. Nigerian Journal of Community Medicine/Primary Health Care, 15, 4-9.

Okpani, A. O., Okpani, J. U. (2000). Sexual activity and contraceptive use among female adolescents. A report from Port Harcourt, Nigeria. African Journal of Reproductive Health, 4(1), 40-47.

Olayinka, B.A., Osho, A.A. (1997). Changes in attitude, sexual behaviour and the risk of HIV/AIDS transmission in Southwest
Nigeria. East African Medical Journal, 74(9), 554-560.

Sacks, M.H., Silberstein, C., Weiler, P, Perry, S.,(1990). HIV related risk factors in acute Psychiatric Inpatients. Hospital Community Psychiatry, 41,449- 451.

Smart, R. G., Hyges, P. H., Johnstone, L. D., Anumonye, A., Khant, U., Medina-Mora M. E., et al. (1980). A methodology for student drug use surveys. Geneva: World Health Organization.

United Nations Programme on HIV/AIDS \& World Health Organization (2008) Report on the global AIDS epidemic. Geneva, Switzerland.

Kaiser, H.J (2009). United States global health policy :The global HIV/AIDS epidemic, Fact Sheet; Kaiser Family Foundation.

Weinhardt, L. S., Carey, M. P., Carey, K. B., Verdecias, R.N. (1999). Increase Assertiveness skill to reduce HIV risk among women living with severe and persistent mental illness. Journal of Consulting and Clinical Psychology, 66, 680- 684. 